\title{
Reversible photoreduction of methylene blue in acrylate media containing benzyl dimethyl ketal
}

\author{
Yulia Galagan ${ }^{\text {a }}$, Wei-Fang $\mathrm{Su}^{\mathrm{a}, \mathrm{b}, *}$ \\ ${ }^{a}$ Department of Materials Science and Engineering, National Taiwan University, N1 Roosevelt Road, Section 4, Taipei, Taiwan \\ ${ }^{\mathrm{b}}$ Graduate Institute of Polymer Science and Engineering, National Taiwan University, N1 Roosevelt Road, Section 4, Taipei, Taiwan
}

Received 10 July 2007; received in revised form 11 September 2007; accepted 2 November 2007

Available online 17 November 2007

\begin{abstract}
The reversible photoreduction of methylene blue in acrylate media is studied here. Methylene blue can be photoreduced using a benzyl dimethyl ketal photoinitiator upon $365 \mathrm{~nm}$ irradiation. The photoreduction is due to the interaction of methylene blue with methyl radical which is generated when benzyl dimethyl ketal is photocleaved. The photoreduced polyacrylate sample exhibits reversible photoreduction behavior due to the cyclic processes of oxidation in air and reduction in nitrogen upon UV exposure. Since methylene blue is widely used across many disciplines, our results have many potential applications in sensors, data storage, electronic devices, etc.
\end{abstract}

(C) 2007 Elsevier B.V. All rights reserved.

Keywords: Methylene blue; Benzyl dimethyl ketal; Photoreduction; Acrylate; Mechanism; Radical; Sensor; Red-ox; Color transition; Thiazine dyes

\section{Introduction}

Methylene blue (tetramethylthionine chloride $\mathrm{C}_{16} \mathrm{H}_{18} \mathrm{ClN}_{3} \mathrm{~S}$ ) (Scheme 1) is a heterocyclic aromatic dye, a member of thiazine dyes. It is broadly used in the different fields of biology, medicine, chemistry, and industry. In biology [1], methylene blue is used as a dye for a number of different staining procedures. It can also be used as an indicator to determine whether cells (such as yeast) are alive or not. The blue indicator turns colorless in the presence of active enzymes, thus indicating living cells. It is also widely used in medicine for its antiseptic properties [2]. The red-ox properties of methylene blue are provided<smiles>CN(C)C1=C[C@H]2C(=C1)N=C([SiH3])c1ccc(N(C)C)cc12</smiles>

methylene blue (MB)

\footnotetext{
* Corresponding author at: Department of Materials Science and Engineering, National Taiwan University, N1 Roosevelt Road, Section 4, Taipei, Taiwan. Tel.: +8862 3366 4078; fax: +886223634562.

E-mail address: suwf@ntu.edu.tw (W.-F. Su).
}

by an ability to accept or donate hydrogen ions. We can take advantage of these properties to treat poisonous chemical substances such as hydrocyanic acid and cyanides, carbon monoxide, nitrites, aniline and its derivatives [3]. Methylene blue is also able to reduce the heme group, converting hemoglobin to methemoglobin [2]. The use of methylene blue as a dye in textile industry [4] has decreased slightly in last few years due to its high light sensitivity. However, it is still widely used for the manufacture of color pens and polygraphic inks [5]. The red-ox properties of methylene blue make a useful indicator in analytical chemistry [6]. Methylene blue is blue when it is in an oxidizing environment, but colorless (leuco methylene blue (LMB)) if it is exposed to a reducing agent:

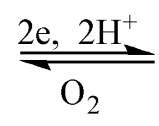

$\mathrm{O}_{2}$<smiles>C1CCC1</smiles><smiles>CN(C)c1ccc2c(c1)Sc1cc(N(C)C)ccc1N2</smiles>

leuco methylene blue (LMB)
The reduction of methylene blue (MB) to leuco methylene blue and its re-oxidation have found applications in numerous modern inventions. Used in industry, the colorimetric oxygen indicators are based on the red-ox reaction of methylene blue [7-14]. 


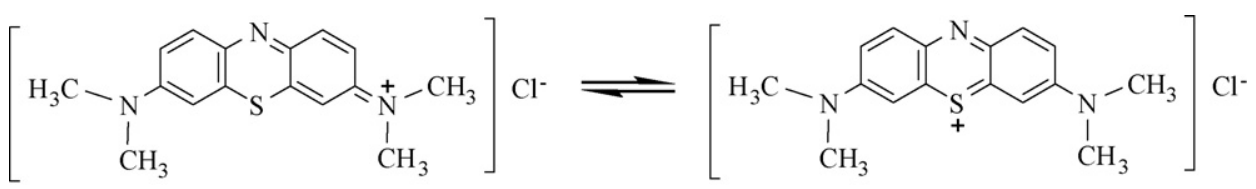

Scheme 1. Structure of methylene blue.

The principle behind the indicator is that the colorless reduced leuco methylene blue (in the absence of oxygen) can be rapidly oxidized in the presence of oxygen to its original color. The reduction and re-oxidation of methylene blue has also found application in data recording and holographic industries $[15,16]$. Optical data storage media with the limited access [17] are also based on the oxidation of leuco dyes (in particular, methylene blue). Many time-indicating apparatuses are based on the color transition properties of reduced redox dyes in the presence of oxygen [18-22]. Such devices provide visual time monitoring via color change. They have wide applications in the food and pharmaceutical industries to ensure freshness and quality control of the products. In these industries, visual color transition can indicate the expiration of documents and passes attached to the products.

The above-mentioned inventions are based on the chemical reduction of methylene blue followed by re-oxidation. The most popular reducing agents include ammonium sulfate, ferrous compounds, sodium hydrosulfite, ascorbic acid, monosaccharides or oligo-saccharides in alkali medium. For example, the most well-known commercial colorimetric oxygen indicators used in food packaging (the Ageless Eye, manufactured by the Mitsubishi Gas Company [13,23]) is based on the chemical reaction of methylene blue with glucose in alkali medium.

However, in the past few years, attention has turned to the photoreduction of methylene blue [24-36]. The photochemical studies of methylene blue illustrates that it has relatively long-lived triplet stage $1 \mathrm{~T}=450 \mu \mathrm{s}$ [37]. This property provides opportunities as an application in the area of singlet oxygen production and reductive electron transfer [24,25]. It is used as a part of the three-component initiating system [25-28] which includes redox dye, amine and iodonium salt. UV-activated methylene blue can be easily reduced to leuco methylene blue by tertiary amines [29,30], sulfinates [31], or ascorbic acid [32]. There are many investigations concerning the photoreduction of methylene blue by $\mathrm{TiO}_{2}[33,34]$. An oxygen indicator comprised of redox dye (methylene blue), semiconductor $\left(\mathrm{TiO}_{2}\right)$ and a sacrificial electron donor (triethanolamine) has also been developed [35,36].

This work is concerned with the reduction of methylene blue by the photoinitiator benzyl dimethyl ketal (BDK) in acrylate media. BDK photoinitiates the polymerization of acrylate monomers while simultaneously reduce the methylene blue to leuco methylene blue. Now we can obtain the leuco form of the dye incorporated into an acrylate matrix as a solid film. Using BDK as a reducing agent alleviates the necessity for using additional reductants such as water (something undesirable in acrylate polymerization). Transparent colorless leuco methylene blue-modified acrylate films are oxygen sensitive and become blue after contacting with oxygen. The blue oxidized films can be photoreduced again into colorless film. This reversible photoreduction behavior with color transition of acrylate films can find wide applications in electro-optic devices, oxygen detecting and time duration monitoring.

\section{Experimental}

The methylene blue used throughout this work was obtained from Acros Organics (Belgium). Photoinitiator 2,2-dimethoxy2-phenyl acetophenone-benzyl dimethyl ketal, was obtained from Ciba Specialty Chemicals (Switzerland). Acrylates: 2-hydroxyethyl methacrylate (HEMA) was obtained from Sigma-Aldrich (USA) and tricyclodecane dimethanol diacrylate (TCDDA) was from Sartomer Co. (USA). All chemicals were used as received without any purification.

An acrylate solution of hydroxyethyl methacrylate and tricyclodecane dimethanol diacrylate in a weight ratio of $1: 1$, with $0.17 \mathrm{wt} . \%$ of methylene blue and $4 \mathrm{wt} . \%$ of photoinitiator was stirred for about $10 \mathrm{~min}$ to obtain a blue solution. Then a $100 \mu \mathrm{m}$ blue thin film was produced on a glass substrate using a draw down rod. The samples were UV irradiated for approximately 4 min under a nitrogen atmosphere. Following irradiation, $100 \mu \mathrm{m}$ acrylate film was obtained. To make acrylate film encapsulated between two glasses, a glass reservoir with a height of $100 \mu \mathrm{m}$ was filled with acrylate/methylene blue/photoinitiator solution, covered by a second glass, and then irradiated.

All UV irradiation was conducted using UV light, provided by 4 W UVGL-25 Mineralight ${ }^{\circledR}$ lamp (UVP, Inc., San Gabriel, CA), $\lambda=365 \mathrm{~nm}$.

All UV/vis spectra were recorded using a Perkin-Elmer Lambda $35 \mathrm{UV} / \mathrm{vis}$ Spectrometer. Scans of the UV/vis spectrum of thin polymer films were taken over the range of 300-900 nm and methanol solutions over the range of 200-900 nm.

\section{Results and discussion}

The acrylate media contains a mixture of HEMA and TCDDA (a ratio of 1:1, w/w). HEMA was chosen because of its hydroxyl functional groups. This hydrophilic acrylate allows methylene blue to be soluble in the acrylate matrix. TCDDA is a low viscosity hydrophobic difunctional acrylate [38] monomer that is polymerized by free radicals. The high $T_{\mathrm{g}}\left(186^{\circ} \mathrm{C}\right)$ of polymerized TCDDA is associated with a small free volume in the matrix which slows down oxygen diffusion in the matrix as compared with the neat HEMA polymer $\left(T_{\mathrm{g}}=65^{\circ} \mathrm{C}\right)$. This allows for a manageable oxidation reaction rate. The chemical structures of acrylates are shown in Scheme 2.

We have used photoinitiator benzyl dimethyl ketal to polymerize acrylate monomers in the presence of methylene blue 
<smiles>C=C(C)C(=O)OCCO</smiles>

2-Hydroxyethyl methacrylate (HEMA)<smiles>C=CC(=O)OCCCC1CC2CCC1C2COC(=O)C=C</smiles>

Tricyclodecane dimethanol diacrylate (TCDDA)

Scheme 2. Chemical structure of acrylate monomers.

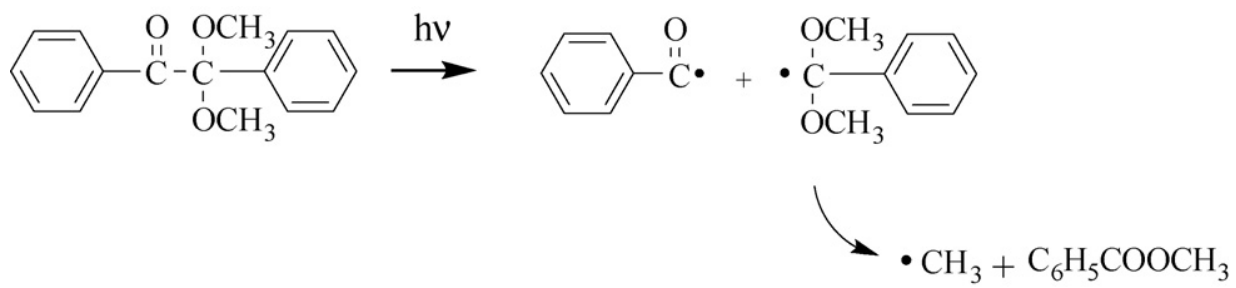

Scheme 3. Photocleavage reactions of photoinitiator benzyl dimethyl ketal.

under UV irradiation at $365 \mathrm{~nm}$. Colorless polyacrylate film where methylene blue was reduced to its leuco derivative was obtained. We would like to understand the reaction mechanism of this photoreduction reaction. The absorption spectra of methylene blue/acrylate/benzyl dimethyl ketal thin films obtained after UV irradiation is shown in Fig. 1. The absorption of methylene blue was diminished in the film. The absorption spectra of BDK, MB and acrylates in methanol are shown in Fig. 2. Methylene blue does not absorb at $365 \mathrm{~nm}$. Only BDK absorbs light and undergoes photocleavage to generate free radicals that polymerize acrylate monomers. BDK as well as other benzoyn esters are able to undergo photocleavage to produce benzoyl and $\alpha$-alkoxy benzyl radicals, as shown in Scheme 3 [39]. $\alpha, \alpha$-Dimethoxy benzyl radical is unstable and readily decomposes into methyl benzoate and methyl radicals.

Of the radicals, the carbon-bearing ones have unpaired electrons. Thus, they can have either electrophilic or nucleophilic character depending on the environment of radical-bearing carbon. The photocleavage of BDK provides the formation of two radicals-benzoyl (acyl) and methyl (alkyl) radicals. The

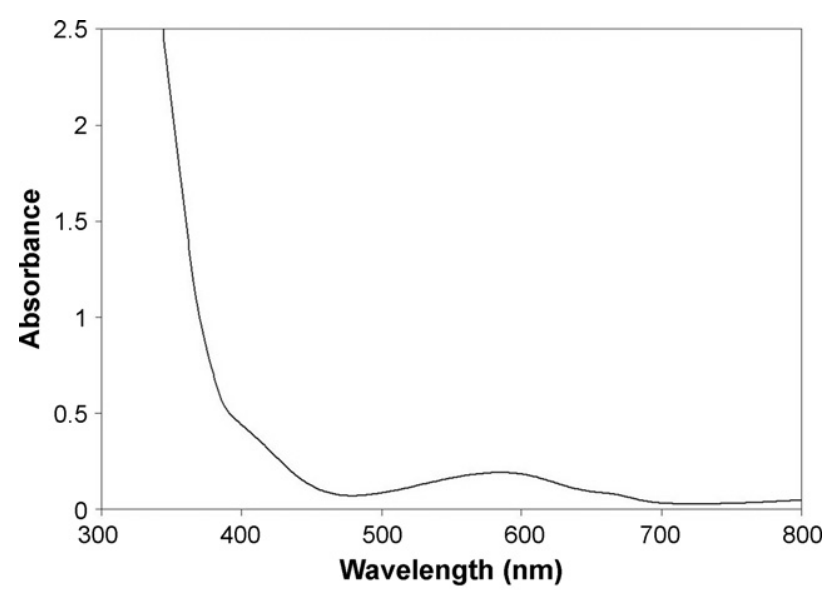

Fig. 1. UV/vis absorption spectra for the methylene blue/acrylate/benzyl dimethyl ketal thin films $(100 \mu \mathrm{m})$ after UV irradiation. acyl free radical has nucleophilic properties that are readily accounted for by considering the localization of the unpaired electron from its nominal $\mathrm{sp}^{2}$ orbital on the carbonyl carbon. The alkyl radical is $\mathrm{sp}^{2}$-hybridized with an accompanying planar geometry at the radical $C$ center. In contrast the hybridized $p$ orbital of the methyl radical has electrophilic character because it contains a single electron. The chloride ion of methylene blue can be easily reacted with active electrophilic methyl radical to generate semi-reduced methylene blue radical and $\mathrm{CH}_{3} \mathrm{Cl}$ as shown in the following equation:

$\mathrm{MB}^{+} \mathrm{Cl}^{-}+{ }^{\bullet} \mathrm{CH}_{3} \rightarrow \mathrm{MB}^{\bullet}+\mathrm{CH}_{3} \mathrm{Cl}$

Two semi-reduced methylene blue radicals can readily disproportionate into methylene blue and leuco methylene blue:

$2 \mathrm{MB}^{\bullet} \rightarrow \mathrm{MB}+\mathrm{LMB}$

At the same time the semi-reduced methylene blue radical can be easily recombined with another nucleophilic radical [40], for example: benzoyl radical to form benzoyl leuco methylene blue

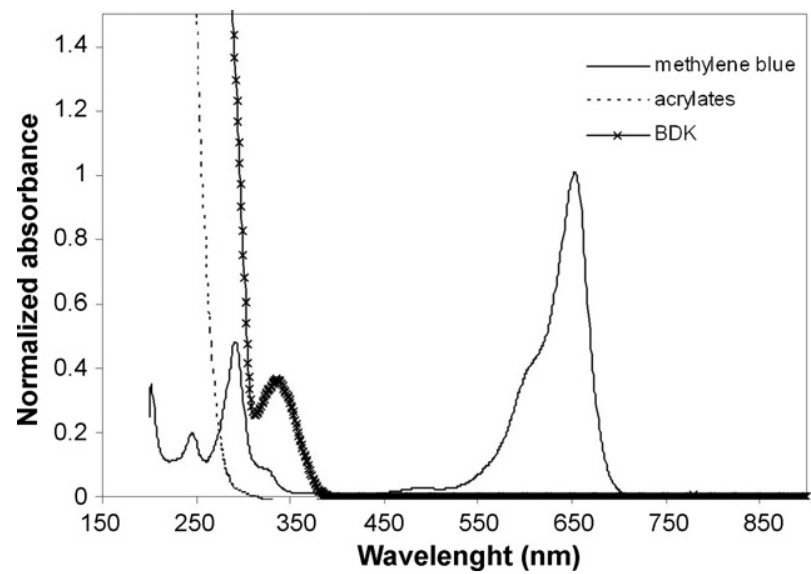

Fig. 2. Normalized absorption spectra of components in the system. All components were dissolved in methanol. Spectra were normalized to absorbance peak of methylene blue taking into account the ratio between the components. 
(BLMB) as shown in the following equation:

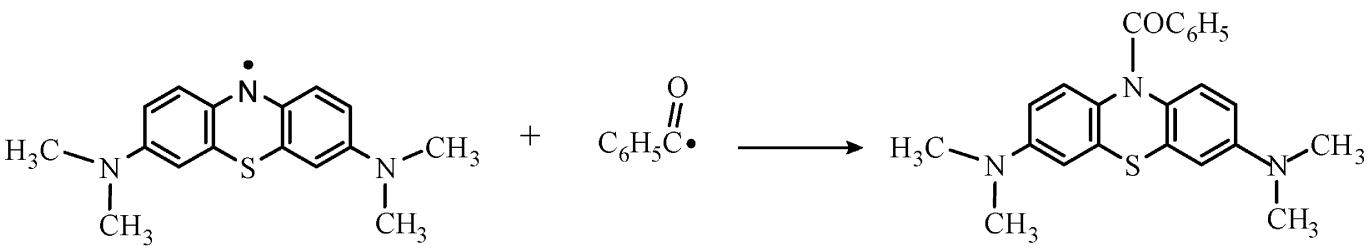

semi-reduced methylene blue

benzoil leuco methylene blue

Therefore, the photoreduction of methylene blue leads to the formation of two dyes: LMB and BLMB. Both of them are colorless and can be readily oxidized by oxygen to MB as shown in the following equations:
(Fig. 1). The stability of the sample is examined in the oxygenfree environment. A hermetically sealed sample was prepared by encapsulating the UV-irradiated BDK/acrylate/methylene blue<smiles>CN(C)c1ccc2c(c1)Sc1cc(N(C)C)ccc1N2</smiles>

leuco methylene blue<smiles>CN(C)c1ccc2nc3ccc(N(C)C)cc3[c-]c2c1</smiles>

methylene blue

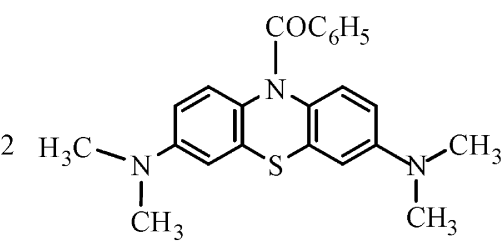

benzoil leuco methylene blue

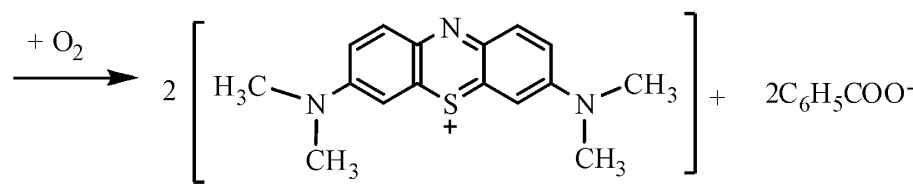

methylene blue
(6)
The photoreduction of methylene blue involves two stages: semi-reduction and full reduction of methylene blue. Fullreduced methylene blue (or leuco methylene blue) is stable in oxygen-free environment. The presence of semi-reduced radicals, according to Eq. (3), leads to its recombination that is accompanied by color change due to the formation of methylene blue. Semi-reduced methylene blue radical absorbs light at $420 \mathrm{~nm}[34,41]$ and the presence of its insignificant amount in the sample is illustrated by the UV/vis spectrum of the film

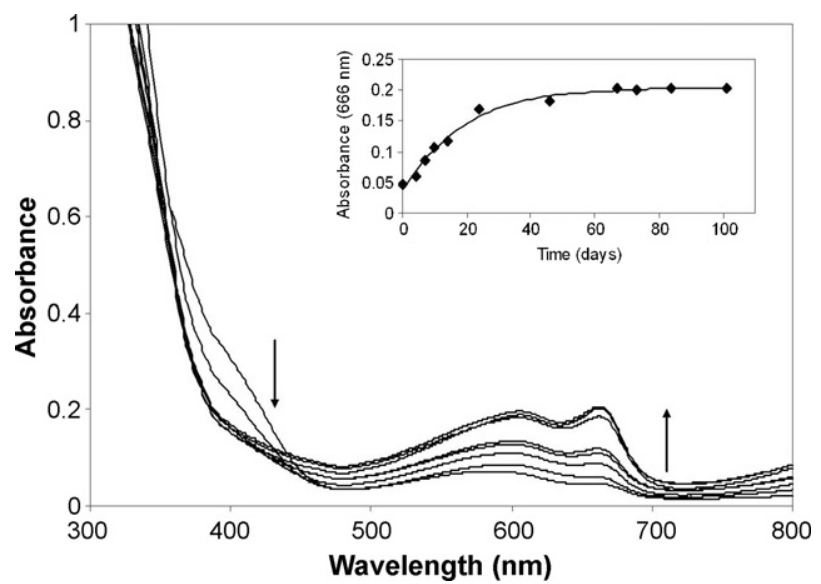

Fig. 3. UV/vis spectral changes during the storage of BDK/acrylate/methylene blue thin film (thickness $100 \mu \mathrm{m}$ ) encapsulated between two glasses, $T=298 \mathrm{~K}$ (inset shows the absorbance change with time). film between two glass plates and sealing its edge with Al-tape. Fig. 3 shows the UV/vis absorbance changes with time. Initially we observed a decrease in absorbance at $420 \mathrm{~nm}$ and an increase in absorbance between 600 and $700 \mathrm{~nm}$ due to the recombination of methylene blue radicals (Eq. (3)). This process was continued until the recombination process reaches its steady state in about 30 days (Fig. 3, inset), it indicates that the methylene blue radical is relatively stable, especially in the solid state [42]. We did not observe any changes at $665 \mathrm{~nm}$ after 30 days of storage. So, oxygen-free storage of the sample illustrates insignificant color transition due to presence of semi-reduced radicals. Leuco methylene blue illustrates high stability at oxygen-free condition and can be easily oxidized in air.

The reversibility of photoreduced methylene blue was studied by exposing the UV-irradiated polyacrylate sample to oxygen. Fig. 4 shows the absorbance between 600 and $700 \mathrm{~nm}$ gradually increasing over time. This type of behavior is appropriate for applications as a time indicator. A maximum absorbance in the $100 \mu \mathrm{m}$ sample was reached after 8 days of exposure. The oxidation speed in the solid sample is much slower than that of the solution due to a diffusion control process. The sample with hermetic-sealed glass packaging was stored for 100 days and still showed a good reaction between reduced methylene blue and oxygen (Fig. 5, right side). A film with the same thickness also reaches maximum absorbance after 8 days of exposure.

UV irradiation of oxidized methylene blue/acrylate film leads to the reduction of methylene blue. The rate of reduction of 


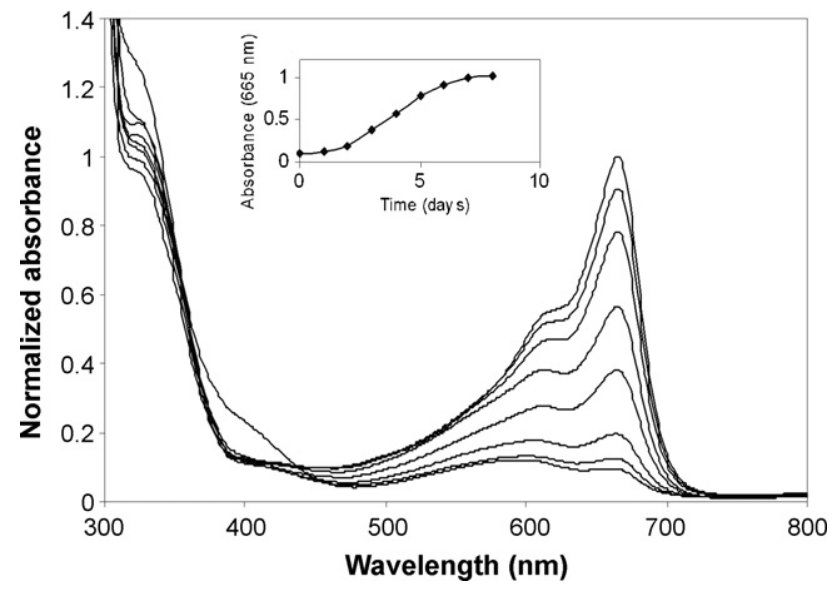

Fig. 4. UV/vis spectra of oxidation reaction of leuco methylene blue recorded for air exposed leuco methylene blue/acrylate thin film; each spectrum was recorded every $24 \mathrm{~h}$.

methylene blue in solid film is much slower than in liquid state. Thus, the same dose of UV which was enough for the photoreduction of methylene blue in liquid acrylate media ( 4 min by $4 \mathrm{~W}$ lamp) can reduce only $10 \%$ of methylene blue based on the absorbance at $665 \mathrm{~nm}$ for an oxidized MB/polyacrylate film as shown in Fig. 6. The UV irradiation leads to an increased absorbance at $420 \mathrm{~nm}$ that is due to the formation of semireduced methylene blue in addition to the decreased absorbance at $665 \mathrm{~nm}$.

The photoreduction of the oxidized film can only be accomplished in the absence of oxygen. A prolonged period of UV irradiation in the presence of oxygen leads to partial decomposition of methylene blue according to the following equation:

$$
\begin{aligned}
\mathrm{C}_{16} \mathrm{H}_{18} \mathrm{~N}_{3} \mathrm{SCl}+25.5 \mathrm{O}_{2} \rightarrow & \mathrm{HCl}+\mathrm{H}_{2} \mathrm{SO}_{4}+3 \mathrm{HNO}_{3} \\
& +16 \mathrm{CO}_{2}+6 \mathrm{H}_{2} \mathrm{O}
\end{aligned}
$$

Fig. 7 illustrates the changes in absorbance at $665 \mathrm{~nm}$ in methylene blue/acrylate films with the cycle process of air oxidation

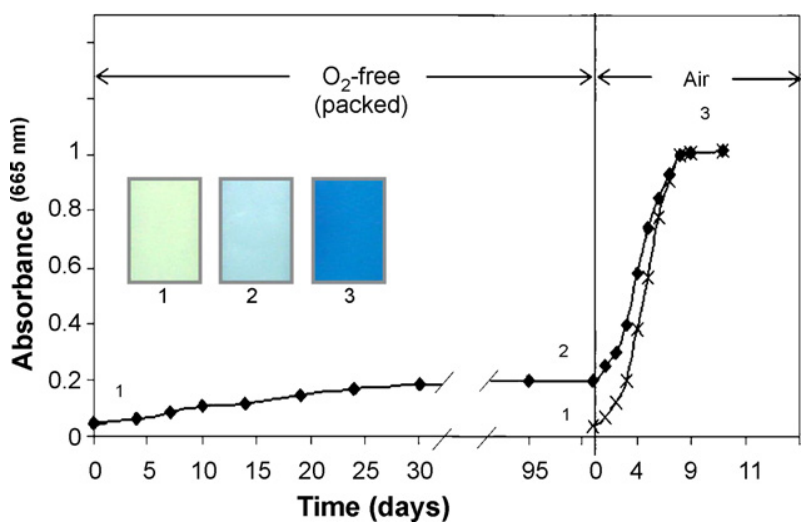

Fig. 5. Absorbance-time relationship of the oxidation reaction of leuco methylene blue in acrylate films [ $\$$ ) 100 days of storage in oxygen-free environment with further oxidation in air; $(x)$ air oxidation just after preparation]. (1) The color of the sample just after preparation; (2) the color after 100 days of storage; (3) the color after oxidation.

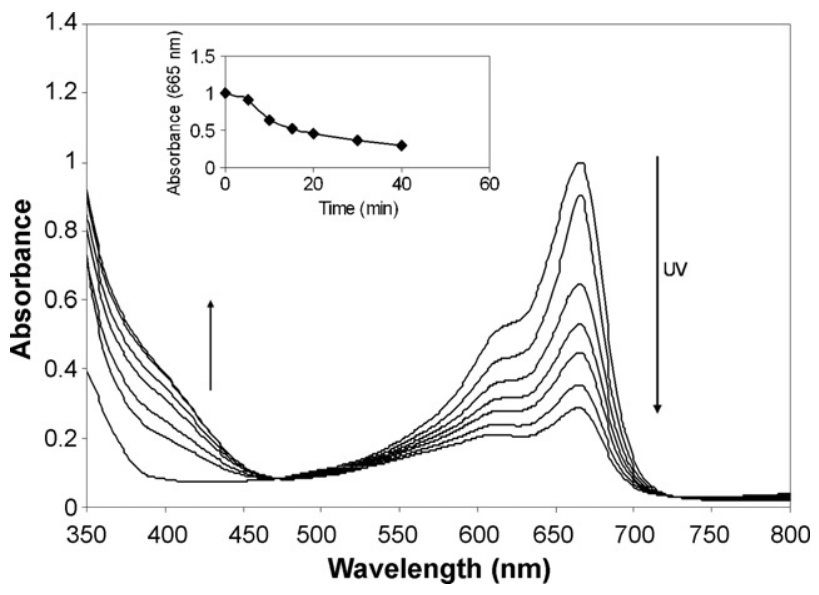

Fig. 6. UV/vis spectra of the reduction of methylene blue recorded for methylene blue/acrylate thin film; each spectrum was recorded after 5, 10, 15, 20, 30 and $40 \mathrm{~min}$ of UV irradiation by $4 \mathrm{~W}$ lamp at $365 \mathrm{~nm}$.

and UV reduction. The methylene blue/acrylate thin film first undergoes irradiation in a nitrogen atmosphere then is exposed to air, which allows it to reach the same absorption intensity as before the irradiation (Fig. 7a). However, the film irradiated by UV in air did not return to its full absorption after oxidization (Fig. 7b). The absorption of methylene blue decreases with increasing cycles in air because of the further decomposition of methylene blue.
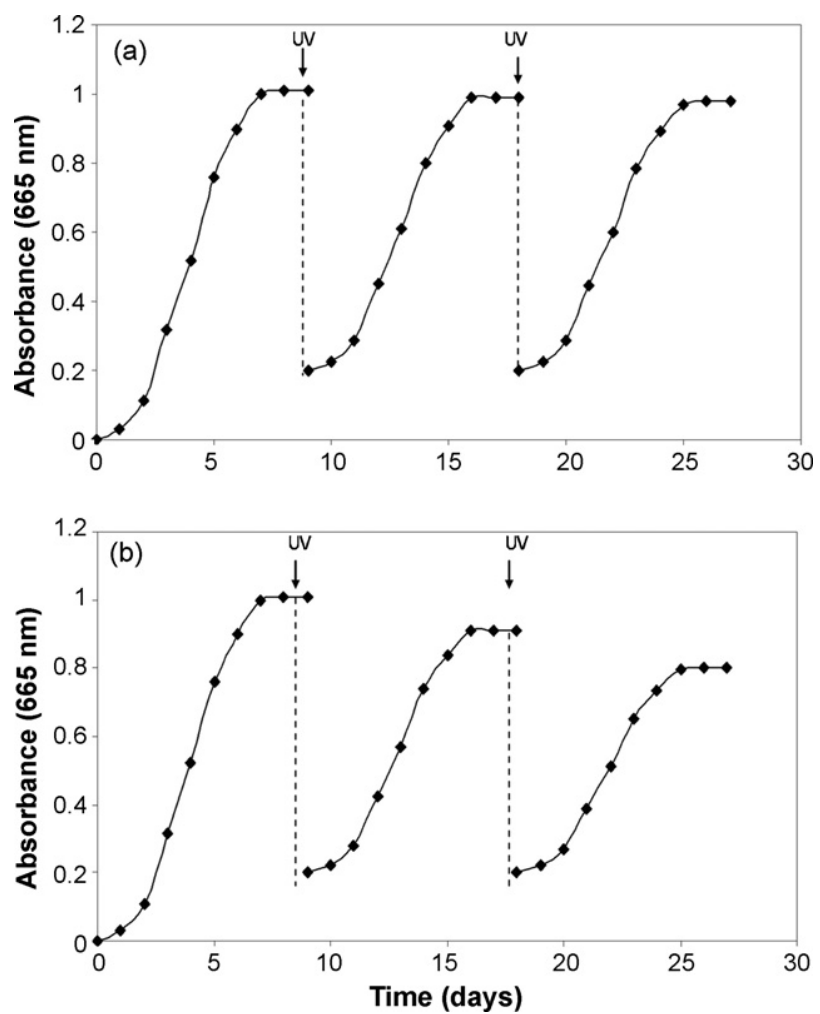

Fig. 7. Absorbance at $665 \mathrm{~nm}$ in methylene blue/acrylate films changed during oxidation and UV reduction. UV irradiation ( $40 \mathrm{~min}$ by $4 \mathrm{~W}$ lamp, on a distance $1 \mathrm{~cm}$ ) was performed either in (a) nitrogen or (b) air. 


\section{Conclusion}

The methylene blue can be photoreduced using benzyl dimethyl ketal in acrylate media. The photoreduction of methylene blue involves two stages. First, the methylene blue reacts with the methyl radical that is generated from the photocleavage of benzyl dimethyl ketal. Electrophilic interaction of methyl radicals with the nucleophilic chloride ion of methylene blue, accompanied with electron transfer to methylene blue generates semi-reduced methylene blue radicals. Second, the semi-reduced methylene blue radical may undergo further reduction by combining itself with another radical in the reaction such as benzoyl radical to form completely reduced leuco methylene blue. The photoreduced methylene blue polyacrylate sample exhibits reversible photoreduction behavior from the cycling process of oxidation in air and reduction in nitrogen upon UV exposure. These results have many potential applications in sensors, data storage, opto-electronic devices and others.

\section{References}

[1] M. Wainwright, M.N. Byrne, M.A. Gattrell, J. Photochem. Photobiol. B 96 (2006) 227-230.

[2] R.H. Schirmer, B. Coulibaly, A. Stich, M. Scheiwein, H. Merkle, J. Eubel, K. Becker, H. Becher, O. Müller, T. Zich, W. Schiek, B. Kouyaté, Redox Rep. 8 (5) (2003) 272-275.

[3] W.J. Allexsaht, Psychiatr. Quart. 12 (1938) 245-252.

[4] S.F. Kang, C.H. Liao, S.T. Po, Chemosphere 41 (2000) 1287-1294.

[5] A. Hideaki, US Patent 6,261,352 (2001).

[6] Y. Dilgin, G. Nişli, Chem. Pharm. Bull. 53 (10) (2005) 1251-1254.

[7] M. Sumitani, H. Inoue, K. Sugito, US Patent 6,703,245 B2 (2004).

[8] Y. Inoue, H. Hatakeyama, I. Yoshino, US Patent 5,358,876 (1994).

[9] M. Sumitani, S. Takagi, Y. Tanamura, H. Inoue, Anal. Sci. 20 (2004) $1153-1157$.

[10] D. Perlman, H. Linschitz, US Patent 4,526,752 (1985).

[11] K.C. Krumhar, M. Karel, US Patent 5,096,813 (1992).

[12] Y. Yoshikawa, T. Nawata, M. Goto, Y. Kondo, US Patent 4,349,509 (1982).

[13] Y. Yoshikawa, T. Nawata, M. Goto, Y. Fujii, US Patent 4,169,811 (1979).

[14] A. Mills, Chem. Soc. Rev. 34 (2005) 1003-1011.
[15] M. Ushamani, K. Sreekumar, C.S. Kartha, R. Joseph, Appl. Opt. 41 (10) (2002) 1984-1988.

[16] M. Ushamani, K. Sreekumar, C.S. Kartha, R. Joseph, Appl. Opt. 43 (18) (2004) 3697-3703.

[17] E.M. Breitung, E.M.S. Van Hamersveld, D.R. Olson, M.B. Wisnudel, US Patent 6,733,950 B2 (2004).

[18] K.H. Hu, J.D. Loconti, US Patent 3,768,976 (1973).

[19] R.M. Gohil, US Patent 0,110,835 (2006).

[20] D. Jackson, US Patent 3,480,402 (1969).

[21] G. Lewis, WO 02/46741 A1 (2002).

[22] W.A. Bullard, D.B. Stahiman, US Patent, 3,963,442 (1976).

[23] D.W. Grattan, M. Gilberg, Stud. Conserv. 39 (3) (1994) 210-214.

[24] J.R. Anthony, K.L. Warczak, T.J. Donohue, PNAS 102 (18) (2005) 6502-6507.

[25] K.S. Padon, A.B. Scranton, J. Polym. Sci. A: Polym. Chem. 38 (2000) 3336-3346.

[26] J. Yang, D.C. Neckers, J. Polym. Sci. A: Polym. Chem. 42 (2004) 3836-3841.

[27] D. Kim, A. Scranton, J. Polym. Sci. A: Polym. Chem. 42 (2004) 5863-5871.

[28] K.S. Padon, A.B. Scranton, J. Polym. Sci. A: Polym. Chem. 38 (2000) 2057-2066.

[29] M. Macchione, G. De Filpo, A. Mashin, F.P. Nicoletta, G. Chidichimo, Adv. Mater. 15 (3) (2003) 327-329.

[30] S. Jockusch, H.-J. Timpe, W. Schnabel, N.J. Turro, J. Photochem. Photobiol. A 96 (1996) 129-136.

[31] L.A. Miller, J.D. Margerum, J.B. Rust, R.G. Brault, A.M. Lacker, Macromolecules 7 (1974) 179-187.

[32] D.F. Eaton, Photogr. Sci. Eng. 23 (1979) 150-154.

[33] A. Mills, J. Wang, J. Photochem. Photobiol. A 127 (1999) 123-134.

[34] N. Tacconi, J. Carmona, K. Rajieshwar, J. Electrochem. Soc. 144 (7) (1997) 2486-2490.

[35] S.K. Lee, M. Sheridan, A. Mills, Chem. Mater. 17 (2005) 2744-2751.

[36] S.K. Lee, A. Mills, A. Lepre, Chem. Commun. (2004) 1912-1913.

[37] S.L. Murov, I. Carmichael, G.L. Hug, Handbook of Photochemistry, 2nd revised ed., Marcel Dekker, New York, 1993.

[38] V.D. Deepak, J. Rajan, S.K. Asha, J. Polym. Sci. A: Polym. Chem. 44 (15) (2006) 4384-4395.

[39] S.P. Pappas, UV Curing: Science and Technology, Technology Marketing Corp., 1985.

[40] R. Muthyala, Chemistry and Applications of Leuco Dyes, Kluwer Academic Publishers, 2002.

[41] O. Impert, A. Katafias, P. Kita, A. Mills, A. Pietkiewicz-Graczyk, G. Wrzeszcz, Dalton Trans. (2003) 348-353.

[42] I. Fridovich, P. Handler, J. Biol. Chem. 235 (1960) 1835-1838. 